Review

\title{
Gamma Hydroxybutyric Acid (GHB) for the Treatment of Alcohol Dependence: A Review
}

\author{
Fabio Caputo $^{1, *}$, Teo Vignoli ${ }^{2}$, Icro Maremmani $^{3}$, Mauro Bernardi ${ }^{2}$ and Giorgio Zoli $^{1}$ \\ 1 Department of Internal Medicine, SS Annunziata Hospital, Cento (Ferrara), Italy; \\ E-Mail: g.zoli@ausl.fe.it \\ 2 "G. Fontana" Centre for the Study and Multidisciplinary Treatment of Alcohol Addiction, \\ Department of Clinical Medicine, University of Bologna, Italy; E-Mails: tvignoli@yahoo.com \\ (T.V.); mauro.bernardi@unibo.it (M.B.) \\ 3 Vincent P. Dole Dual Diagnosis Unit, Santa Chiara University Hospital, Department of Psychiatry, \\ NPB, University of Pisa, Italy; E-Mail: info@aucns.org
}

* Author to whom correspondence should be addressed; E-Mail: f.caputo@ausl.fe.it

Received: 15 May 2009 / Accepted: 21 June 2009 / Published: 24 June 2009

\begin{abstract}
Gamma-hydroxybutyric acid (GHB) is a short-chain fatty acid structurally similar to the inhibitory neurotransmitter $\gamma$-aminobutyric acid. Clinical trials have demonstrated that $50-100 \mathrm{mg} / \mathrm{kg}$ of GHB fractioned into three or six daily doses is able to suppress alcohol withdrawal symptoms and facilitates the maintenance of abstinence from alcohol. These studies have also shown that GHB craving episodes are a very limited phenomenon (about 10-15\%). Thus, physicians with access should consider the clinical efficacy of GHB as a valid pharmacological tool for the treatment of alcohol addiction.
\end{abstract}

Keywords: gamma-hydroxybutyric acid; alcohol withdrawal syndrome; anti-craving drug

\section{Introduction}

Gamma hydroxybutyric acid (GHB) was synthesized in 1960 in an attempt to create an analogue of the ubiquitous inhibitory brain neurotransmitter gamma-aminobutyric acid (GABA) that would cross the blood-brain barrier [1-3]. GHB was first developed as a central nervous system depressant [4,5] 
and used as an anesthetic adjuvant for minor surgical procedures in laboratory as well as in clinical settings [6-11]. The use of GHB as an anesthetic is now decreasing, even though it is still approved in Germany for intravenous anesthesia [1]. In the 1970s, GHB was found to be effective in the treatment of narcolepsy [12-15]. In particular, nightly doses of GHB were shown to improve the structure of sleep in narcoleptic patients, reducing the number of nocturnal awakenings and daytime attacks of cataplexy [16-18]. In the United States, through a limited distribution program, the FDA approved GHB as a Schedule III Controlled Substance to treat a small subset of patients with narcolepsy who have episodes of weak or paralyzed muscles (i.e. cataplexy) [19]. In addition, since 1992, GHB has been approved in Italy and Austria as a treatment for alcohol dependence [20].

\section{Metabolism}

GHB occurs naturally in mammalian brain tissue [21]. The primary precursor of GHB in the brain is GABA, which is transformed into succinic semialdehyde (SSA) through a GABA-transaminase and then converted into GHB via a specific succinic semialdehyde reductase (SSR). GHB can be reconverted to SSA via a GHB dehydrogenase, and then SSA can be converted back to GABA (Figure 1); SSA can also be transformed by succinic semialdehyde dehydrogenase (SSADH) into succinic acid and then further metabolized via the Krebs Cycle in mitochondria (Figure 1). GHB is primarily eliminated by the liver, and only a modest quantity of it remains unmodified (2-5\%) and eliminated with urine and/or by a still not fully ascertained process of beta-oxidation (Figure 1) [21].

Figure 1. GHB metabolism in the central nervous system.

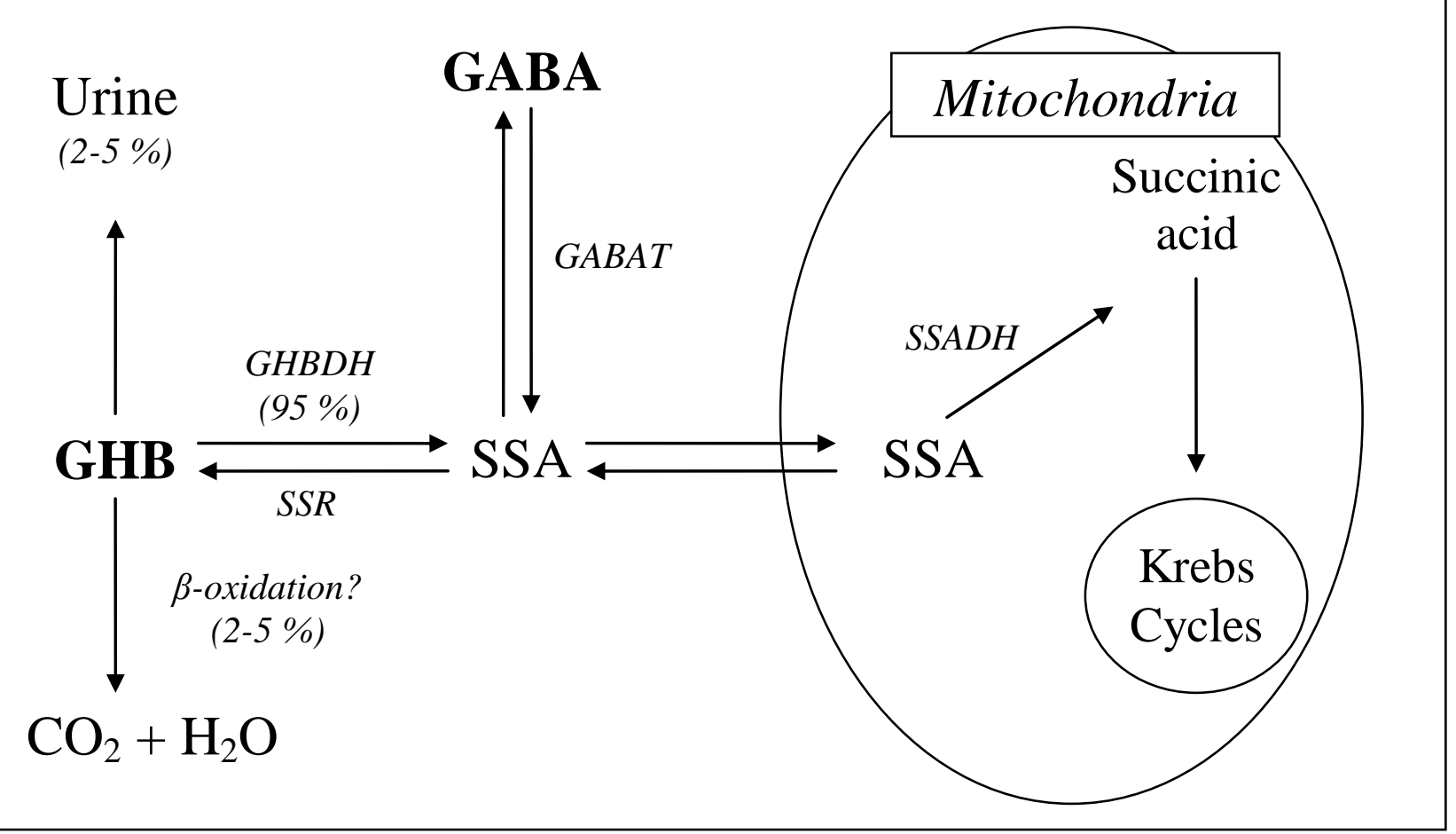

GHBDH: GHB dehydrogenase; SSR: succinic semialdehyde reductase; SSA: succinic semialdehyde; GABA: gamma-aminobutyric acid; GABAT: GABA-transaminase; SSADH: succinic semialdehyde dehydrogenase. 
Exogenous GHB is rapidly absorbed by the gastro-intestinal tract; its peak plasma concentration appears after 15-45 minutes, and its clinical effects after 15-20 minutes. This drug has a dosedependent elimination half-life; in healthy subjects this can vary from 20 to 53 minutes [22].

\section{Neuro-Modulatory Properties}

In the central nervous system, GHB binds to $\mathrm{GHB}$ and $\mathrm{GABA}_{\mathrm{B}}$ receptors with high and low affinity, respectively [21]. The endogenous neurobiological activity of GHB is mediated through the GHB receptor, while many of the pharmacological and clinical effects of exogenously administered GHB appear to be mediated through the $\mathrm{GABA}_{\mathrm{B}}$ receptor, where GHB may act both directly, as a partial $\mathrm{GABA}_{\mathrm{B}}$ receptor agonist, and indirectly through GHB-derived GABA [1,21]. Irrespective of the brain GHB concentration, it is far from certain that GHB interacts directly with the $\mathrm{GABA}_{\mathrm{A}}$ receptors $[1,21,22]$. However, the conversion of exogenously administered GHB to GABA induces an activation of $\mathrm{GABA}_{\mathrm{B}}$ receptor and $\mathrm{GABA}_{\mathrm{A}}$ receptors too $[1,21,22]$ and this is responsible of $\mathrm{GHB}$ sedative and anxiolitic effects.

Physiologically, the mesocorticolimbic dopaminergic neurons (DA) are involved in rewarddependent learning (Figure 2a). DA have their cell bodies in the ventral tegmental area (VTA) and project into the basal forebrain structures, such as the nucleus accumbens (NAc), amygdala, and frontal and limbic cortexes [21]. Activation of DA, with a resultant increase in the output of dopamine in innervated projection structures, has been reported with virtually all major drugs of abuse. It is supposed that the alcohol-mimetic effect of GHB appears to be related to the effects of the dopamine increase mediated by $\mathrm{GABA}_{\mathrm{B}}$ receptors in mesocorticolimbic circuitry [21].

Figure 2. Activity of meso-corticolimbic system in physiological condition (a), and during exogenous administration of GHB (b).

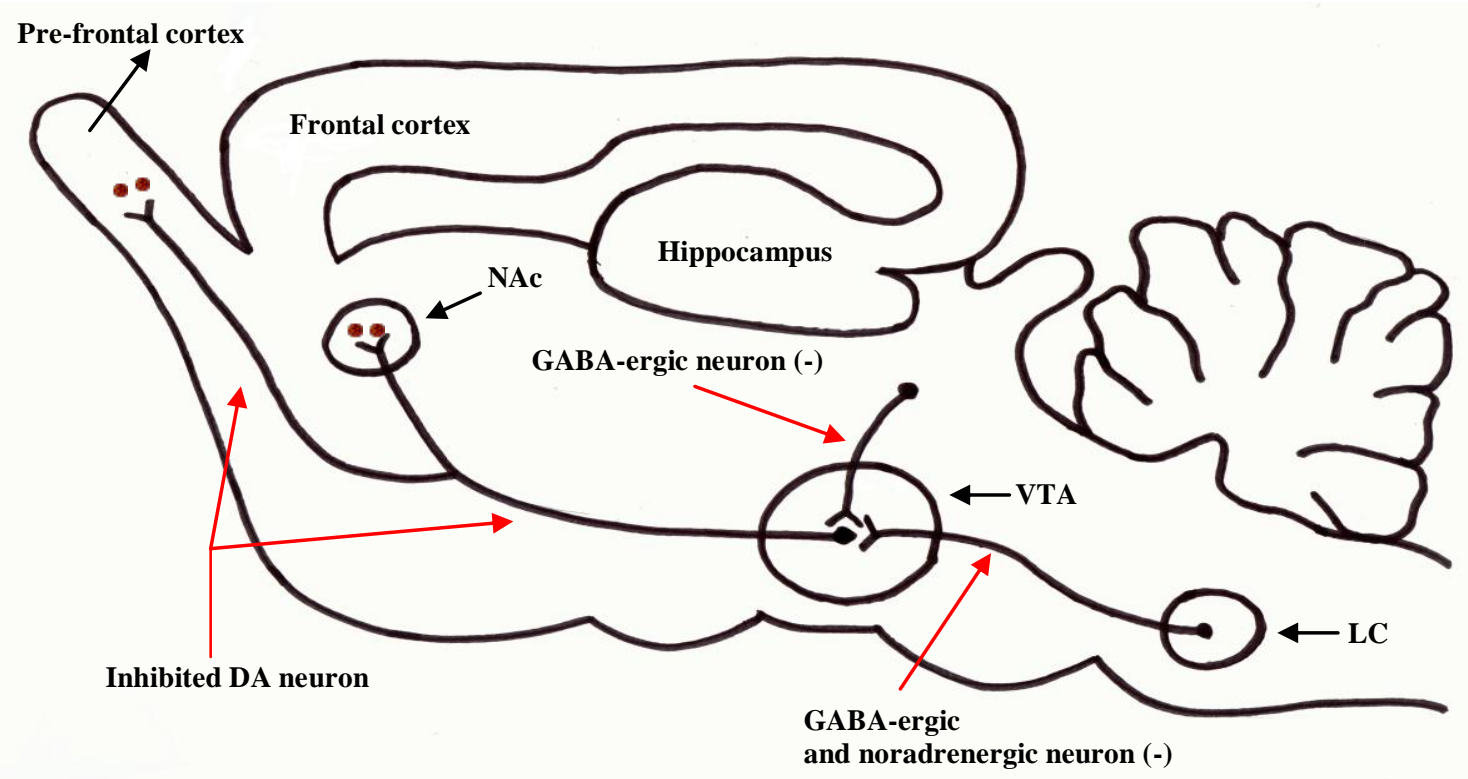


Figure 2. Cont.

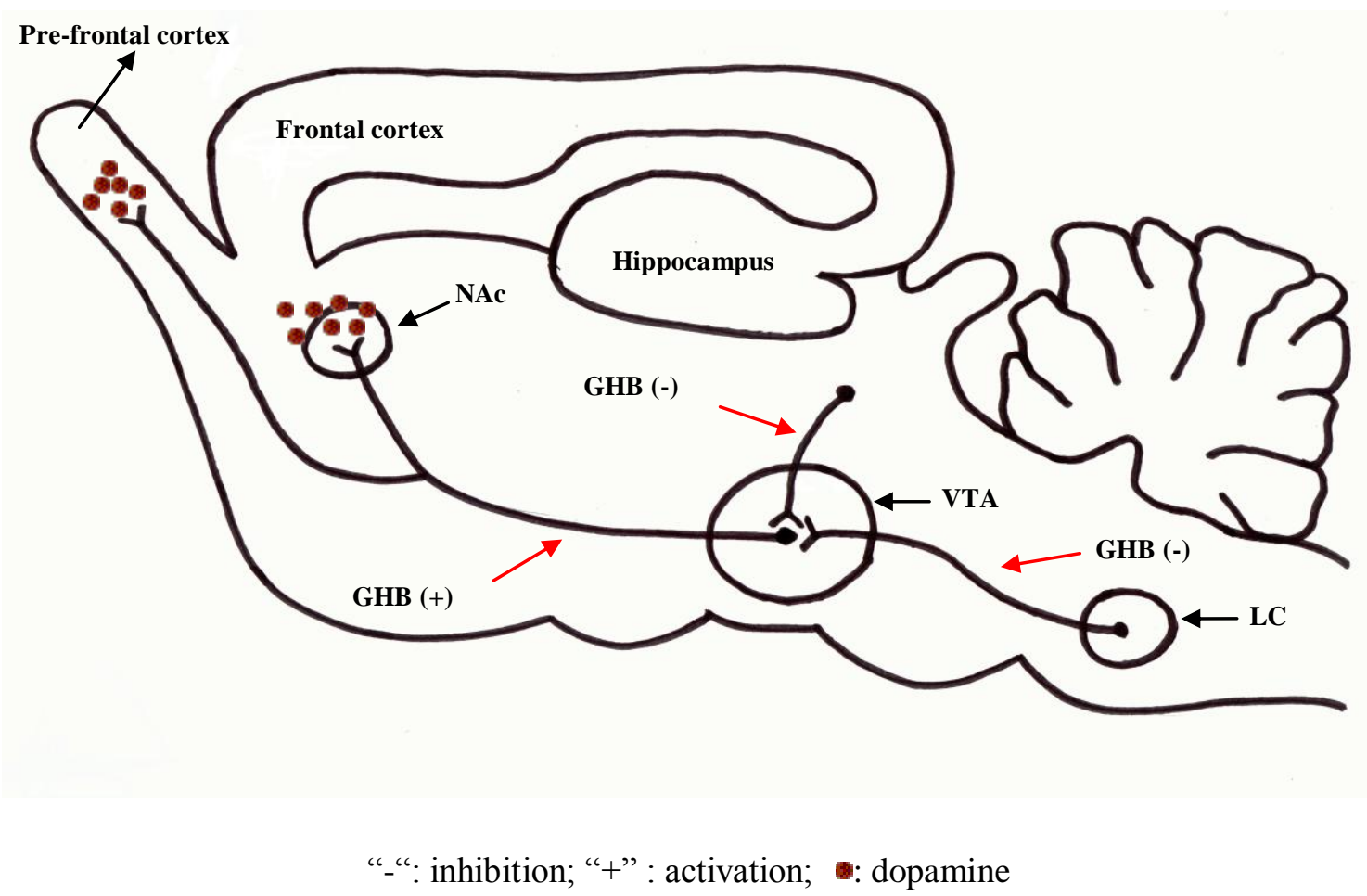

(a) dopaminergic neurons (DA) originate from ventral tegmental area (VTA) and project their fibres to the nucleus accumbens (NAc) and to the pre-frontal cortex; DA neurons play a relevant role in physiological reward (i.e. food, sleeping, sexual activity); this circuit is often inhibited by noradrenergic and GABA-ergic neurons originated from the locus ceruleus (LC).

(b) GHB induces dis-inhibition of DA originated from VTA through DA direct activation and inhibition of GABA-ergic and noradrenergic neurons with a consequent increase in dopamine release from NAc and pre-frontal cortex; this mechanism is on the basis of the alcohol-mimicking effect of GHB.

Both endogenous and exogenous forms of GHB have a dual action on the GHB receptors and the $\mathrm{GABA}_{B}$ receptors. GHB that binds with high affinity to the pre-synaptic GHB receptors decreases the release of GABA, while GHB that binds with a low-affinity site on the $G_{A B} A_{B}$ receptors increases activation of cell-surface receptors. Therefore, the administration of exogenous GHB is primarily able to decrease the release of GABA from the pre-synaptic GABA-ergic neurons through effects mediated by a direct activation of GHB receptors [21]. The result would be disinhibition of DA of the VTA with increased dopamine within that circuitry, and this is responsible of the alcohol mimic effect of GHB (Figure 2b) [21]. Finally, GHB has been recently shown to decrease the activity of neurons in the locus ceruleus (LC), providing yet another route by which GHB could disinhibit mesocorticolimbic DA (Figure 2b) [21].

In summary, data indicate that sedative effect of exogenously administered GHB (high dose) may be due to a direct effect on $\mathrm{GABA}_{\mathrm{B}}$ and indirect on $\mathrm{GABA}_{\mathrm{A}}$ receptors: mainly $100 \mathrm{mg} / \mathrm{kg} / \mathrm{day}$ to suppress alcohol withdrawal syndrome (AWS) and from 4 to $9 \mathrm{~g} /$ day to treat cataplexy in narcoleptic patients. On the other hand, the alcohol-mimic mechanism of exogenously administered GHB (low dose) may be due to a decrease in the release of GABA through the effects mediated by GHB receptors on pre-synaptic GABA-ergic and noradrenergic neurons, with a resultant disinhibition of DA and 
increase in dopaminergic activity in the mesocorticolimbic circuitry (Figure 2b) [21]: mainly $50 \mathrm{mg} / \mathrm{kg} /$ day to suppress craving for alcohol intake.

\section{GHB for the Treatment of Alcohol Withdrawal Syndrome}

AWS is mediated by a reduced GABA-ergic activity in the central nervous system [25-27]. Exogenous GHB suppresses AWS symptoms in humans by an indirect activation of $\mathrm{GABA}_{\mathrm{A}}$ receptors due to the conversion of GHB to GABA [21]. Such a GABA-ergic activity triggers chloride transport across the neuronal membrane, thus inducing a decreased neuronal excitability [28] with consequent resolution of AWS symptoms.

In the clinical area, the efficacy of a non-benzodiazepine GABA-ergic compound such as GHB in suppressing AWS is well demonstrated [29]. After the first pilot study [30], a single-blind trial comparing GHB versus diazepam did not show a significant different efficacy of these drugs in suppressing AWS [31], even though GHB reduced anxiety, agitation and current depression more rapidly than diazepam [31]. A more recent study, however, demonstrated that GHB was even more effective than diazepam in treating AWS [32]. GHB has also been found to be equally efficient as clomethiazole [33], and its efficacy was further confirmed by treating AWS in almost three hundred hospitalized patients affected by different conditions, such as for medical, neurological or psychiatric diseases, trauma or surgery [34]. In all these studies, GHB was employed at the dose of 50-100 mg/kg divided into three or four daily administrations, and no serious side effects were reported.

\section{GHB as an Anti-Craving Drug in the Maintenance of Alcohol Abstinence}

\subsection{Studies with GHB as Mono-Therapy}

As mentioned above, GHB exerts an ethanol-mimicking effect on the central nervous system [35-37]. Consistent with this rationale, GHB has been shown to be capable of inhibiting voluntary ethanol consumption in rats that have a preference for ethanol [35,37,38]. In humans, a randomized double-blind study treating patients with GHB at dose of $50 \mathrm{mg} / \mathrm{kg}$ (divided into three daily administrations) or placebo for three months showed that GHB was significantly superior to placebo in increasing the number of abstinent days, in reducing the number of daily drinks and in reducing alcohol craving [39]. Another open multi-centre study confirmed the efficacy of GHB in improving the abstinence rate and in reducing craving for alcohol [40]. GHB also proved to be manageable, with few side-effects, such as dizziness, sleepiness and tiredness early on during treatment (usually resolved after 2-3 weeks). Despite these results, about 30-40\% of alcoholics treated with GHB fail to achieve complete abstinence from alcohol even though they sometimes describe a temporary reduction of alcohol craving. Taking into account the short half-life of GHB [22,23], a study was, then, conducted to investigate the efficacy of the administration of a greater fractioning (six times a day) of the same dose $(50 \mathrm{mg} / \mathrm{kg})$ of GHB in those subjects who have not achieved alcohol abstinence after the administration of three daily doses of this drug [41]. The results showed a significant reduction of alcohol craving in a greater percentage of alcoholics who were able to achieve complete abstinence from alcohol. 
More recently, a one-year open-label study tested the efficacy of GHB (doses ranging between 25 and $100 \mathrm{mg} / \mathrm{kg} /$ day) in "treatment-resistant" chronic alcoholics defined as patients who have previously followed at least two attempts at treatment [i.e. use of psychoactive drugs such as selective serotonin reuptake inhibitors, mood stabilizers, tricycles and/or self-help group intervention] without achieving alcohol abstinence or those who relapsed into heavy drinking during attendance at self-help groups or who were not helped in achieving alcohol abstinence by their precarious psycho-social or environmental conditions [42]. The results of the study showed that $60 \%$ of patients were "responders", i.e., patients who successfully achieved complete abstinence from alcohol together with social adjustment (full-responders) or patients who reduced their alcohol intake but did not accomplish complete alcohol abstinence (partial-responders) [42]. The retention rate during treatment with GHB was, therefore, significantly higher than the retention rate of the same sample treated with previous pharmaco-therapies. Furthermore, this study confirmed that the only significant predictor of the retention rate was the six-times/daily fractionated administration of GHB [42], a result in close agreement with the previous study [41].

Laboratory studies with healthy subjects investigating the effects of administering alcohol and a single dose of GHB $50 \mathrm{mg} / \mathrm{kg}$ together showed an increased rate of side-effects, probably due to the combination of GHB and alcohol [43]. This effect was not observed in the clinical studies with alcoholics reported above. In fact, no side effects due to the combination of GHB $50 \mathrm{mg} / \mathrm{kg}$ (divided into 3 to 6 daily administration) and alcohol were observed in those GHB-treated alcoholics who were still drinking during the treatment [39-41,44,45]. It is conceivable that the use of the same dose of $50 \mathrm{mg} / \mathrm{kg}$ divided into 3-6 daily administrations was able to prevent the occurrence of unsafe effects when associated with ethanol [46].

\subsection{Comparative Studies}

A 3-month open randomized comparative study evaluating the efficacy of oral doses of GHB (50 $\mathrm{mg} / \mathrm{kg}$ of body weight t.i.d) compared with oral doses of naltrexone (NTX) (50 mg/day) in maintaining abstinence from alcohol in patients mostly with moderate dependence showed a better efficacy with GHB than NTX $(66.7 \%$ vs $35.3 \%$, P < 0.02) [44]. Nevertheless, in the same study, in the NTX group patients who failed to be abstinent did not relapse into heavy drinking, confirming the ability of this drug to reduce alcohol relapses, while in the GHB group all the patients who did not maintain abstinence relapsed into heavy drinking $(\sim 11 \%)$. Craving for GHB was not observed, and no sedative additive effects due to alcohol and GHB interaction in patients who relapsed, drug withdrawal syndrome or side effects due to drug suspension on drug discontinuation were shown. Moreover, a 12-month comparative study showed that, despite a trend in favor of GHB, this drug administered at a dose of $50 \mathrm{mg} / \mathrm{kg} /$ day, NTX at a dose of $50 \mathrm{mg} /$ day, and disulfiram at a dose of $200 \mathrm{mg} /$ day proved to have a similar effect in maintaining alcohol abstinence at the end of treatment, 65\%, 49\% and 40\%, respectively [47]. None of the patients belonging to the GHB group developed craving for this drug, and side-effects were well tolerated in all groups. 


\subsection{Combined Studies}

Considering the data emerging from the comparative studies, one hypothesis arose: are GHB and NTX able to work better if combined together, taking advantage of the former's alcohol-mimicking effect and the latter's anti-reward property? In order to confirm this suggestion, a 3-month randomized study was performed in patients mostly with severe alcohol dependence [45]. In this 3-month open randomized comparative study, the combined treatment of GHB and NTX was shown to be more effective in maintaining abstinence from alcohol than GHB and NTX used singly, $72.2 \%, 40 \%$ and $5.9 \%$, respectively [45]. The number of relapses into heavy drinking also tended to occur less frequently in the combination group (no cases) than in either the GHB group or the NTX group. These data support the above-mentioned preliminary hypothesis suggesting that the two drugs may combine their different actions synergistically without suppressing the favorable effects of each other. In addition, as demonstrated by the absence of patients who developed craving for GHB in the combined group with respect to the group taking GHB alone ( 10\%) [45], it may be hypothesized that a modulation effect induced by the anti-reward property of NTX is able to avoid the onset of craving for GHB as previously also demonstrated by three clinical experiences [48]. Another 6-month open randomized study evaluating whether GHB or NTX or its combination could help to maintain alcohol abstinence in patients following a treatment with escitalopram, an anti-depressant agent belonging to the category of selective serotonin reuptake inhibitors, has also been performed [49]. In this study the combination therapy in association with escitalopram proved to be more efficient in preventing alcohol relapses than GHB plus escitalopram, NTX plus escitalopram or escitalopram given alone, 83.3\%, $50 \%, 33.3 \%$, and $18.1 \%$, respectively [49]. In fact, the craving mechanism implicated in alcohol addiction may differ in different subtypes of alcohol-dependent patients [50,51]. In particular, dopaminergic/opioidergic deregulation has been implicated in reward craving, GABA ergic/glutamatergic deregulation in relief craving, and serotonergic deregulation in obsessive craving [50-52]. It is possible that different craving conditions and profiles co-exist in a single patient, which is why drug combinations (association of GHB, NTX and escitalopram) could be more effective than mono-therapy in reducing relapses. An understanding of the different forms of craving could have important implications particularly in the field of anti-craving drug therapy.

\section{Craving for and Abuse of GHB in Clinical Studies}

Craving for and abuse of GHB remains one of the crucial points during the use of this drug. However, episodes of craving for GHB in alcoholics, when manifested, are a very limited phenomenon (about 10\%) [53]; on the other hand, it is to be hoped that better manageability and safety of GHB can probably be improved with the identification of groups of alcoholics more predisposed to develop this unfavorable effect. A study investigating the risk of developing craving for and abuse of GHB among different types of alcoholics was, therefore, performed [54]. In this study, indeed, 47 patients were enrolled and divided into four different sub-types of alcoholics, and treated with an oral dose of GHB (50 mg/kg of body weight fractioned into three daily administrations) for three months. At the end of the study, besides a general efficacy of GHB in maintaining alcohol abstinence in all four groups of patients, craving for GHB was statistically significantly higher in those alcoholics with previous 
cocaine dependence than in "pure" alcoholics (patients with a diagnosis of alcohol dependence without other addictive disorders) (90\% vs 14.3\%, P < 0.001), with 60\% abuse of it [54]; however, craving for GHB did not differ between "pure" alcoholics and alcoholics with previous heroin dependence except for the fact that all alcoholics with previous heroin dependence abused GHB, while none of the "pure" alcoholics manifested this addiction. The greater incidence of craving for and abuse of GHB in alcoholics with a previous diagnosis of cocaine or heroin dependence is an interesting finding and may be putatively explained by the alteration of dopamine system [55]. It has been clearly described that patients with previous chronic exposure to heroin or cocaine may present a down-regulation of $\mathrm{D}_{1}$ and $\mathrm{D}_{2}$ receptors, and only high doses of GHB (> $50 \mathrm{mg} / \mathrm{kg} / \mathrm{die}$ ) may exert a reward effect [56,57]. Moreover, imaging studies with positron emission tomography have shown that chronic exposure to cocaine, alcohol or opiates down regulates $\mathrm{D}_{2}$ receptors in striatum, and these adaptations may persist for a long time after substance cessation [58]. In addition, chronic exposure to cocaine reduces $\mathrm{GABA}_{\mathrm{B}}$ receptor activity in the meso-cortico-limbic area $[59,60]$. The consequence is a reduction in dopamine release, which persists after cocaine cessation. As GHB acts on GABA $\mathrm{B}_{\mathrm{B}}$ receptors, it is likely that alcoholics with previous cocaine addiction present a down-regulated $G_{B B} A_{B}$ system and are more predisposed to develop craving and episodes of abuse of GHB. Thus, GHB, a GABA receptor agonist, may act as a substitutive drug, so that alcoholics with previous cocaine or heroin addiction tend to become predisposed to misuse of the drug. Interestingly, in the above mentioned study [54], alcoholics following a methadone maintenance treatment (MMT) program did not develop craving for GHB. As some recent studies have shown that MMT may induce a $\mu$-opioid receptor desensitization in rats [61] and a long-lasting striatum dopamine neuron impairment in heroin users [62], a dopamine independent pathway may be responsible for these results; the low percentage of subjects who failed to maintain abstinence for alcohol in the MMT group may confirm this hypothesis.

\section{Conclusions}

Available studies have demonstrated that GHB appears to be effective both in the management of AWS and in the maintenance of long-term abstinence from alcohol [63,64]. Moreover, it is worth noting that all the cited clinical trials have clearly demonstrated that GHB discontinuation is not followed by withdrawal syndrome, irrespective of its use for treating AWS or maintaining abstinence from alcohol; therefore, the discontinuation of GHB does not require a tapering procedure [65]. None of the above-mentioned trials reported serious side effects during the treatment of GHB; in addition, the fractioning of the GHB doses, from three to six daily administrations, avoided the occurrence of additive sedative effects in patients who voluntarily use alcohol during the treatment with this drug [44-46]. Moreover, due to its short half-life (4-6 hours) [23], GHB may be also safe in patients with decompensated liver disease with ascites effusion [24]; however, this data needs to be confirmed by further clinical trials. Furthermore, even though rare and transitory episodes of sedation due to GHB abuse have been reported, no cases of intoxication, coma or deaths have occurred when the drug is administered under a medical supervision [40,54]. On the other hand, when GHB is used as a recreational drug of abuse (non-clinical use), several cases of intoxication and even death after a single and self-administered dose of the "street" formulation have been reported [66-68]. 
In conclusion, we believe that specialists in the treatment of alcohol addiction should be less concerned by the risk of GHB intoxication when this drug is employed for treating alcoholism under close medical surveillance. They should not be discouraged from using GHB in the treatment of alcohol addiction, as long as some rules are followed during its administration: a) not exceeding $50-100 \mathrm{mg} / \mathrm{kg}$ fractioned into three to six daily administrations; b) using GHB only for the treatment of pure alcoholics, and avoiding this drug for those alcoholics with previous cocaine or heroin dependence; c) planning strict medical surveillance (weekly visits) and designating a family member to whom GHB should be entrusted [69]. The safety and efficacy of GHB, thus, need to be emphasized, as this drug represents a most useful tool for treating alcohol dependence [70,71].

\section{References}

1. Carter, L.P.; Koek, W.; France, C.P. Behavioral analyses of GHB: receptor mechanisms. Pharmacol. Ther. 2009, 121, 100-114.

2. Gianoulakis, C. Implication of endogenous opioids and dopamine in alcoholism: human and basic science studies. Alcohol Alcoholism 1996, 31, 33-42.

3. Bessmann, S.P.; Fishbein, W.M. Gamma-hydroxybutyric, a normal brain metabolite. Nature 1963, 200, 1207-1208.

4. Laborit, H.; Jouany, J.M.; Gerard, J.; Fabiani, F. Summary of an experimental and clinical study on a metabolic substrate with inhibitory central action: sodium 4-hydroxybutyrate. Presse Medicale 1960, 68, 1867-1869.

5. Benavides, J.; Rumigny, J.F.; Bourguignon, J.J.; Cash, C.; Wermuth, C.G.; Mandel, P.; Vincendon, G.; Maitre, M. High affinity binding sites for gamma-hydroxybutyric acid in rat brain. Life Sci. 1982, 30, 953-961.

6. Snead, O.C.; Liu, C.C. Gamma-hydroxybutyric acid binding sites in rat and human brain synaptosomal membranes. Biochem. Pharmacol. 1984, 33, 2587-2590.

7. Andriamampandry, C.; Taleb, O.; Viry, S.; Muller, C.; Humbert, J.P.; Gobaille, S.; Aunis, D.; Maitre, M. Cloning and characterization of a rat brain receptor that binds the endogenous neuromodulator gamma-hydroxybutyrate (GHB). FASEB J. 2003, 17, 1691-1693.

8. Andriamampandry, C.; Taleb, O.; Kemmel, V.; Humbert, J.P.; Aunis, D.; Maitre, M. Cloning and functional characterization of a gamma-hydroxybutyrate receptor identified in the human brain. FASEB. J. 2007, 21, 885-895.

9. Aldrete, J.A.; Barnes, D.P. 4-Hydroxybutyrate anaesthesia for cardiovascular surgery. A comparison with halothane. Anaesthesia 1968, 23, 558-565.

10. Kleinschmidt, S.; Grundmann, U.; Janneck, U.; Kreienmeyer, J.; Kulosa, R.; Larsen, R. Total intravenous anaesthesia using propofol, gamma-hydroxybutyrate or midazolam in combination with sufentanil for patients undergoing coronary artery bypass surgery. Eur. J. Anaesthesiol. 1997, 14, 590-599.

11. Kleinschmidt, S.; Grundmann, U.; Knocke, T; Silomon, M; Bach, F; Larsen, R. Total intravenous anaesthesia with gamma-hydroxybutyrate $(\mathrm{GHB})$ and sufentanil in patients undergoing coronary artery bypass graft surgery: a comparison in patients with unimpaired and impaired left ventricular function. Eur. J. Anaesthesiol. 1998, 15, 559-564. 
12. Kemmel, V.; Miehe, M.; Roussel, G.; Taleb, O.; Nail-Boucherie, K.; Marchand, C.; Stutz, C.; Andriamampandry, C.; Aunis, D.; Maitre, M. Immunohistochemical localization of a GHB receptor-like protein isolated from rat brain. J. Comp. Neurol. 2006, 498, 508-524.

13. Carai, M.A.; Colombo, G.; Brunetti, G.; Melis, S.; Serra, S.; Vacca, G.; Mastinu, S.; Pistuddi, A.M.; Solinas, C.; Cignarella, G.; Minardi, G.; Gessa, G.L. Role of GABAB receptors in the sedative/hypnotic effect of $\gamma$-hydroxybutyric acid. Eur. J. Pharmacol. 2001, 428, 315-321.

14. Mamelak, M.; Escrui, J.M.; Stokan, O. The effects of $\gamma$-hydroxybutyrate on sleep. Biol. Psychiatry. 1977, 12, 273-278.

15. Mamelak, M.; Scharf, M.B.; Woods, M. Treatment of narcolepsy with gamma-hydroxybutyrate. A review of clinical and sleep laboratory findings. Sleep 1986, 9, 285-289.

16. Carai, M.A.; Colombo, G.; Reali, R.; Serra, S.; Mocci, I.; Castelli, M.P.; Cignarella, G.; Gessa, G.L. Central effects of 1, 4-butanediol are mediated by GABAB receptors via its conversion into $\gamma$-hydroxybutyric acid. Eur. J. Pharmacol. 2002, 441, 157-163.

17. Broughton, R.; Mamelak, M. Effects of nocturnal gamma-hydroxybutyrate on sleep/waking patterns in narcolepsy-cataplexy. Can. J. Neurol. Sci. 1980, 7, 23-31.

18. Dauvilliers, Y.; Arnulf, I.; Mignot, E. Narcolepsy with cataplexy. Lancet 2007, 369, 499-511.

19. Tunnicliff, G.; Raess, B.U. Gamma-hydroxybutyrate (orphan medical). Curr. Opin. Investig. Drugs 2002, 3, 278-283.

20. Beghè, F.; Campanini, M.T. Safety and tolerability of gamma-hydroxybutyric acid in the treatment of alcohol-dependents patients. Alcohol 2000, 20, 223-225.

21. Snead, O.C., III; Gibson, K.M. Gamma-hydroxybutyric acid. N. Engl. J. Med. 2005, 352, 2721-2732.

22. Palatini, P.; Tedeschi, L.; Frison, G.; Padrini, R.; Zordan, R.; Orlando, R.; Gallimberti, L.; Gessa, G.L.; Ferrara, S.D. Dose-dependent absorption and elimination of gamma-hydroxybutyric acid in healthy volunteers. Eur. J. Clin. Pharmacol. 1993, 45, 353-356.

23. Ferrara, S.D.; Zotti, S.; Tedeschi, L.; Frison, G.; Castagna, F.; Gallimberti, L.; Gessa, G.L.; Palatini, P. Pharmacokinetics of gamma-hydroxybutyric acid in alcohol dependent patients after single and repeated oral doses. Br. J. Clin. Pharmacol. 1992, 34, 231-235.

24. Ferrara, S.D.; Tedeschi, L.; Frison, G.; Orlando, R.; Mazzo, M.; Zordan, R.; Padrini, R.; Palatini, P. Effect of moderate or severe liver dysfunction on the pharmacokinetics of gammahydroxybutyric acid. Eur. J. Clin. Pharmacol. 1996, 50, 305-310.

25. Davies, M. The role of GABAA receptors in mediating the effects of alcohol in the central nervous system. J. Psychiatry Neurosci. 2003, 28, 263-274.

26. Nie, Z.; Madamba, S.G.; Siggins, G.R. Ethanol inhibits glutamatergic neurotransmission in nucleus accumbens neurons by multiple mechanisms. J. Pharmacol. Exp. Ther. 1994, 271, 1566-1573.

27. Snead, O.C., III; Liu, C.C. GABAA receptor function in the $g$-hydroxybutyrate model of generalized absence seizures. Neuropharmacology 1993, 32, 401-409.

28. Malcolm, R.J. GABA systems, benzodiazepines, and substance dependence. J. Clin. Psychiatry 2003, 64, 36-40. 
29. Leggio, L.; Kenna, G.A.; Swift, R.M. New developments for the pharmacological treatment of alcohol withdrawal syndrome. A focus on non-benzodiazepine GABAergic medications. Prog. Neuropsychopharmacol. Biol. Psychiatry 2008, 32, 1106-1117.

30. Gallimberti, L.; Canton, G.; Gentile, N.; Ferri, M.; Cibin, M.; Ferrara, S.D.; Fadda, F.; Gessa, G.L. Gamma-hydroxybutyric acid for treatment of alcohol withdrawal syndrome. Lancet 1989, 2, 787-789.

31. Addolorato, G.; Balducci, G.; Capristo, E.; Attilia, M.L.; Taggi, F.; Gasbarrini, G.; Ceccanti, M. Gamma- hydroxybutyric acid (GHB) in the treatment of alcohol withdrawal syndrome: a randomized comparative study versus benzodiazepine. Alcohol Clin. Exp. Res. 1999, 23, 1596-1604.

32. Nava, F.; Premi, S.; Manzato, E.; Campagnola, W.; Lucchini, A.; Gessa, G.L. Gammahydroxybutyrate reduces both withdrawal syndrome and hypercortisolism in severe abstinent alcoholics: an open study vs. diazepam. Amer. J. Drug Alcohol Abuse 2007, 33, 379-392.

33. Nimmerrichter, A.A.; Walter, H.; Gutierrez-Lobos, K.E.; Lesch, O.M. Double blind controlled trial of $\gamma$-hydroxybutyrate and clomethiazole in the treatment of alcohol withdrawal. Alcohol Alcoholism 2002, 37, 67-73.

34. Korninger, C.; Roller, R.E.; Lesch, O.M. Gamma-hydroxybutyric acid in the treatment of alcohol withdrawal syndrome in patients admitted to hospital. Acta. Med. Austriaca. 2003, 3, 83-86.

35. Agabio, R.; Colombo, G.; Loche, A.; Lobina, C.; Pani, M.L.; Reali, R.; Gessa, G.L. Gammahydroxybutyric acid reducing effect on ethanol intake: evidence in favour of a substitution mechanism. Alcohol Alcoholism 1998, 33, 465-474.

36. Colombo, G.; Agabio, R.; Lobina, C.; Reali, R.; Fadda, F.; Gessa, G.L. Cross tolerance to ethanol and gamma-hydroxybutyric acid. Eur. J. Pharmacol. 1995, 273, 235-238.

37. Gessa, G.L.; Agabio, R.; Carai, M.A.; Lobina, C.; Pani, M.; Reali, R.; Colombo, G. Mechanism of the anti-alcohol effect of gamma-hydroxybutyric acid. Alcohol 2000, 20, 271-276.

38. Biggio, G.; Cibin, M.; Diana, M.; Fadda, F.; Ferara, S.D.; Gallimberti, L.; Gessa, G.L.; Mereu, G.P.; Rossetti, Z.L.; Serra, M. Suppression of voluntary ethanol intake in rats and alcoholics by gamma-hydroxybutyric acid: a non-GABAergic mechanism. Adv. Biochem. Psychopharmacol. 1992, 47, 281-288.

39. Gallimberti, L.; Ferri, M.; Ferrara, S.D.; Fadda, F.; Gessa, G.L. Gamma-hydroxybutyric acid in the treatment of alcohol dependance: a double-blind study. Alcohol. Clin. Exp. Res. 1992, 16, 673-676.

40. Addolorato, G.; Castelli, E.; Stefanini, G.F.; Casella, G.; Caputo, F.; Marsigli, L.; Bernardi, M.; Gasbarrini, G. An open multicentric study evaluating 4-hydroxybutyric acid sodium salt in the medium-term treatment of 179 alcohol dependent subjects. GHB Study Group. Alcohol Alcoholism 1996, 31, 341-345.

41. Addolorato, G.; Cibin, M.; Caputo, F.; Capristo, E.; Gessa, G.L.; Stefanini, G.F.; Gasbarrini, G. Gamma-hydroxybutyric acid in the treatment of alcoholism: dosage fractioning utility in nonresponder alcoholic patients. Drug Alcohol Depend. 1998, 53, 7-10.

42. Maremmani, I.; La Manna, F.; Tagliamone, A. Long-term therapy using GHB (sodium gamma hydroxybutyrate) for treatment-resistant chronic alcoholics. J. Psychoactive Drug. 2001, 33, 135-142. 
43. Thai, D.; Dyer, J.E.; Benowitz, N.L.; Haller, C.A. Gamma-hydroxybutyrate and ethanol effects and interactions in humans. J. Clin. Psychopharmacol. 2006, 26, 524-529.

44. Caputo, F.; Addolorato, G.; Lorenzini, F.; Domenicali, M.; Greco, G.; Del Re, A.; Gasbarrini, G.; Stefanini, G.F.; Bernardi, M. Gamma-hydroxybutyric acid versus naltrexone in maintaining alcohol abstinence: an open randomized comparative study. Drug Alcohol Depend. 2003, 70, 85-91.

45. Caputo, F.; Addolorato, G.; Stoppo, M.; Francini, S.; Vignoli, T.; Lorenzini, F.; Del Re, A.; Comaschi, C.; Andreone, P.; Trevisani, F.; Bernardi, M. Comparing and combining gammahydroxybutyric acid (GHB) and naltrexone in maintaining abstinence from alcohol: An open randomised comparative study. Eur. Neuropsychopharmacol. 2007, 17, 781-789.

46. Caputo, F.; Stoppo, M.; Vignoli, T.; Francini, S.; Lorenzini, F.; Bernardi, M. Use of alcohol during the treatment of alcohol dependence with gamma-Hydroxybutyric Acid: Risk of severe events are avoided by the dose fractioning of the drug. J. Clin. Psychopharmacol. 2007, 27, 418.

47. Nava, F.; Premi, S.; Manzato, E.; Lucchini, A. Comparing treatments of alcoholism on craving and bio-chemical measures of alcohol consumptions. J. Psychoactive Drug. 2006, 38, 211-217.

48. Caputo, F.; Vignoli, T.; Lorenzini, F.; Ciuffoli, E.; Del Re, A.; Stefanini, G.F.; Addolorato, G.; Trevisani, F.; Bernardi, M. Alcoholism Treatment Study Group. Suppression of craving for $\gamma$ hydroxybutyric acid by naltrexone administration: three case reports. Clin. Neuropharmacol. 2005, 28, 87-89.

49. Stella, L.; Addolorato, G.; Rinaldi, B.; Capuano, A.; Berrino, L.; Rossi, F.; Maione, F. An open randomized study of the treatment of escitalopram alone and combined with $\gamma$-hydroxybutyric acidand naltrexone in alcoholic patients. Pharmacol. Res. 2008, 57, 312-317.

50. Verheul, R.; van Den Brink, W.; Geerlings, P. A three-patways psychological model of craving for alcohol. Alcohol Alcoholism 1999, 34, 197-222.

51. Addolorato, G.; Abenavoli, L.; Leggio, L.; Gasbarrini, G. How many cravings? Pharmacological aspects of craving treatment in alcohol addiction: a review. Neuropsychobiology 2005, 51, 59-66.

52. Leggio, L.; Kenna, G.A.; Fenton, M.; Bonenfant, E.; Swift, R.M. Typologies of alcohol dependence from jellinek to genetics and beyond. Neuropsychol. Rev. 2009, doi: 10.1007/s11065-008-9080.

53. Addolorato, G.; Caputo, F.; Capristo, E.; Stefanini, G.F.; Gasbarrini, G. Gamma-hydroxybutyric acid efficacy, potential abuse, and dependence in the treatment of alcohol addiction. Alcohol 2000, 20, 217-222.

54. Caputo, F.; Francini, S.; Stoppo, M.; Lorenzini, F.; Vignoli, T.; Del Re, A.; Comaschi, C.; Leggio, L.; Addolorato, G.; Zoli, G.; Bernardi, M. Incidence of craving for and abuse of gammahydroxybutyric acid (GHB) in different populations of treated alcoholics: an open comparative study. J. Psychopharmacol. 2009, doi: 10.1177/0269881108094620.

55. Kalivas, P.W.; Volkow, N.D. The neural basis of addiction: A pathology of motivation and choice. Am. J. Psychiatry 2005, 162, 1403-1413.

56. Rosen, M.I.; Pearsall, H.R.; Woods, S.W.; Kosten, T.R. Effects of gamma-hydroxybutyric acid (GHB) in opioid-dependent patients. J. Subst. Abuse Treat. 1997, 14, 149-154.

57. Anderson, S.M.; Pierce, R.C. Cocaine-induced alterations in dopamine receptor signalling: implications for reinforcement and reinstatement. Pharmacol. Ther. 2005, 106, 389-403. 
58. Volkow, N.D.; Fowler, J.S.; Wang, G.J.; Swanson, J.M. Dopamine in drug abuse and addiction: results from imaging studies and treatment implications. Mol. Psychiatry 2004, 9, 557-569.

59. Xi, Z.X.; Ramamoorthy, S.; Shen, H.; Lake, R.; Samuvel, D.J.; Kalivas, P.W. GABA transmission in the nucleus accumbens is altered after withdrawal from repeated cocaine. J. Neurosci. 2003, 23, 3498-3505.

60. Jayaram, P.; Steketee, J.D. Effects of repeated cocaine on medial prefrontal cortical GABAB receptor modulation of neurotransmission in the mesocorticolimbic dopamine system. $J$. Neurochem. 2004, 90, 839-847.

61. Martin, T.J.; Kahn, W.R.; Xiao, R.; Childers, S.R. Differential regional effects of methadone maintenance compared to heroin dependence on mu-opioid receptor desensitization in rat brain. Synapse 2007, 61, 176-184.

62. Shi, J.; Zhao, L.Y.; Copersino, M.L.; Fang, Y.X.; Chen, Y.; Tian, J.; Deng, Y.; Shuai, Y.; Jin, J.; $\mathrm{Lu}, \mathrm{L}$. PET imaging of dopamine transporter and drug craving during methadone maintenance treatment and after prolonged abstinence in heroin users. Eur. J. Pharmacol. 2007, 28, 160-166.

63. Johnson, B.A.; Swift, R.M.; Addolorato, G.; Ciraulo, D.A.; Myrick, H. Safety and efficacy of GABAergic medications for treating alcoholism. Alcohol. Clin. Exp. Res. 2005, 29, 248-254.

64. Tambour, S.; Quertemont, E. Preclinical and clinical pharmacology of alcohol dependence. Fundam. Clin. Pharmacol. 2007, 21, 9-28.

65. Addolorato, G.; Caputo, F.; Leggio, L.; Vignoli, T.; Abenavoli, L.; Lorenzini, F.; Bernardi, M.; Gasbarrini, G. Gamma hydroxybutyric acid (GHB) withdrawal does not occur at therapeutic dosage. Drug. Alcohol. Depend. 2005, 77, 209.

66. Nicholson, K.L.; Blaster, R.L. GHB: a new and novel drug of abuse. Drug Alcohol Depend. 2000, $63,1-22$.

67. Ricaurte, G.A.; McCann, U.D. Recognition and management of complications of new recreational drug use. Lancet 2005, 365, 2137-2145.

68. Knudsen, K.; Greter, J.; Verdicchio, M. High mortality rates among GHB abusers in Western Sweden. Clin. Toxicol. 2008, 46, 187-192.

69. Caputo, F.; Addolorato, G.; Trevisani, F.; Bernardi, M. Gamma-hydroxybutyrate as a treatment for alcoholism. Lancet 2005, 366, 981-982.

70. Addolorato, G.; Leggio, L.; Ferrulli, A.; Caputo, F.; Gasbarrini, A. The therapeutic potential of gamma-hydroxybutyric acid for alcohol dependence: balancing the risks and benefits. A focus on clinical data. Expert. Opin. Investig. Drug. 2009, 18, 1-12.

71. Caputo, F.; Bernardi, M.; Zoli, G. Treatment of alcohol use disorders. Lancet 2009, 373, 1519.

(C) 2009 by the authors; licensee Molecular Diversity Preservation International, Basel, Switzerland. This article is an open-access article distributed under the terms and conditions of the Creative Commons Attribution license (http://creativecommons.org/licenses/by/3.0/). 